\title{
Selenofuranoside Ameliorates Memory Loss in Alzheimer-Like Sporadic Dementia: AChE Activity, Oxidative Stress, and Inflammation Involvement
}

\author{
Cristiano Chiapinotto Spiazzi, ${ }^{1}$ Melina Bucco Soares, ${ }^{1}$ \\ Aryele Pinto Izaguirry, ${ }^{1}$ Laura Musacchio Vargas, ${ }^{1}$ Mariane Magalhães Zanchi, ${ }^{1}$ \\ Natasha Frasson Pavin, ${ }^{1}$ Ricardo Ferreira Affeldt, ${ }^{2}$ Diogo Seibert Lüdtke, ${ }^{2}$ \\ Marina Prigol, ${ }^{3}$ and Francielli Weber Santos ${ }^{1}$ \\ ${ }^{1}$ Laboratório de Biotecnologia da Reprodução (Biotech), Universidade Federal do Pampa (UNIPAMPA), Campus Uruguaiana, \\ 97500-970 Uruguaiana, RS, Brazil \\ ${ }^{2}$ Instituto de Química, Universidade Federal do Rio Grande do Sul (UFRGS), Avenida Bento Gonçalves 9500, \\ 91501-970 Porto Alegre, RS, Brazil \\ ${ }^{3}$ Laboratório de Avaliações Farmacológicas e Toxicológicas Aplicadas às Moléculas Bioativas (LaftamBio), \\ Universidade Federal do Pampa (UNIPAMPA), Campus Itaqui, 97.650-000 Itaqui, RS, Brazil
}

Correspondence should be addressed to Francielli Weber Santos; francielliweber@yahoo.com.br

Received 10 December 2014; Revised 17 April 2015; Accepted 10 May 2015

Academic Editor: Neelam Khaper

Copyright (c) 2015 Cristiano Chiapinotto Spiazzi et al. This is an open access article distributed under the Creative Commons Attribution License, which permits unrestricted use, distribution, and reproduction in any medium, provided the original work is properly cited.

\begin{abstract}
Alzheimer's disease (AD) is becoming more common due to the increase in life expectancy. This study evaluated the effect of selenofuranoside (Se) in an Alzheimer-like sporadic dementia animal model. Male mice were divided into 4 groups: control, $\mathrm{A} \beta$, Se, and $\mathrm{A} \beta+$ Se. Single administration of $\mathrm{A} \beta$ peptide (fragments $25-35 ; 3 \mathrm{nmol} / 3 \mu \mathrm{L}$ ) or distilled water was administered via intracerebroventricular (i.c.v.) injection. Selenofuranoside $(5 \mathrm{mg} / \mathrm{kg}$ ) or vehicle (canola oil) was administered orally $30 \mathrm{~min}$ before $\mathrm{A} \beta$ and for 7 subsequent days. Memory was tested through the Morris water maze (MWM) and step-down passive-avoidance (SDPA) tests. Antioxidant defenses along with reactive species (RS) were assessed. Inflammatory cytokines levels and AChE activity were measured. SOD activity was inhibited in the A $\beta$ group whereas RS were increased. AChE activity, GSH, and IL- 6 levels were increased in the $\mathrm{A} \beta$ group. These changes were reflected in impaired cognition and memory loss, observed in both behavioral tests. Se compound was able to protect against memory loss in mice in both behavioral tests. SOD and AChE activities as well as RS and IL-6 levels were also protected by Se administration. Therefore, Se is promising for further studies.
\end{abstract}

\section{Introduction}

Alzheimer's disease (AD) is a chronic neurodegenerative pathology mainly related to aging and it represents the most common form of dementia [1]. It is characterized by its progressive and slow deterioration in cognition, memory, functional ability, behavior, and mood.

Several mechanisms are involved in $\mathrm{AD}$ pathology, such as the presence of neurofibrillary tangles, inflammation processes, and neuronal degeneration. Nevertheless, one of the major characteristics of $\mathrm{AD}$ is the presence of senile plaques in brain regions. These plaques are formed by a dense core of aggregated amyloid- $\beta(\mathrm{A} \beta)$ peptide. This peptide is formed by proteolytic process of amyloid precursor protein (APP) by the action of $\beta$-secretase and $\gamma$-secretase, and it may vary between 39 and 43 amino acid residues [2].

The 25-35 A $\beta\left(\mathrm{A} \beta_{25-35}\right)$ fragment is regarded as the cytotoxic sequence of the parent peptide due to its high level of aggregation, and it retains the toxicity of the total length of the peptide. Possibly, its toxicity may be influenced by the redox state of terminal- $\mathrm{C}$ methionine [3], which could be affected by high levels of reactive species. 
Furthermore, many studies have demonstrated the relationship between $\mathrm{AD}$ and neuroinflammation, which may be a consequence of a systemic inflammatory process that occurs throughout life, mainly related to proinflammatory cytokines such as tumor necrosis factor alpha (TNF- $\alpha)$, interleukin 6 (IL-6), and interleukin $1 \beta$ (IL-1 $\beta$ ) [4]. This process is usually accompanied by an increase in reactive oxygen species (ROS) and oxidative stress.

Therefore, many efforts to treat and prevent the progress of $\mathrm{AD}$ have focused in the use of anti-inflammatory and antioxidant compounds. In this scenario, studies on organoselenium compounds have demonstrated both antioxidant and anti-inflammatory properties. Carbohydrate derivatives have emerged as a class of compounds for potential studies, due to its chemical similarity to naturally occurring molecules. Regarding the selenofuranoside compound, a simple carbohydrate that contains a single Se molecule, Vargas et al. [5] demonstrated its effectiveness in restoring $\delta$-ALA-D enzyme activity in the ovaries of mice exposed to cadmium. Furthermore, Wollenhaupt et al. [6] recently demonstrated that seleno and telluroxylofuranosides protected against toxicity induced by manganese over the nematode Caenorhabditis elegans, leading to nuclear translocation of the transcription factor DAF-16/FOXO, regulating the worms' response to stress, aging, and metabolism. Also, other organoselenium compounds have demonstrated to possess the ability to restore memory loss and cognition impairment induced by $\mathrm{A} \beta$ or streptozotocin intracerebroventricular injection $[7,8]$.

Thus, the aim of this study is to evaluate selenofuranoside, a synthetic organoselenium compound, in a model of Alzheimer-like sporadic dementia induced by intracerebroventricular injection of $\mathrm{A} \beta_{25-35}$ in mice, with reference to its possible antioxidant and anti-inflammatory effects and the ability to improve memory loss and impaired cognition.

\section{Material and Methods}

2.1. Chemicals. Glutathione reductase, $\beta$-nicotinamide adenine dinucleotide phosphate reduced tetrasodium salt (NADPH), 5,5'-dithiobis (2-nitrobenzoic acid) (DTNB), reduced glutathione (GSH), glutathione disulfide (GSSG), and amyloid-beta peptide (fragment 25-35) $\left(\mathrm{A} \beta_{25-35}\right)$ were purchased from Sigma-Aldrich (St. Louis, MO, USA). 1Chloro-2,4-dinitrobenzene (CDNB) was purchased from Aldrich Chemical Co. (USA). Selenofuranoside (Se) was synthesized according to Braga et al. [9] (Figure 1).

The $\mathrm{A} \beta$ peptide was dissolved in sterile filtered water and it was aggregated by incubation at $37^{\circ} \mathrm{C}$ for 4 days before use. Selenofuranoside was dissolved in canola oil.

2.2. Animals and Treatments. Adult male Swiss albino mice (25-30 g) were used for this experiment. The animals were kept in an appropriate cabinet for animals with forced air ventilation, in a 12 -hour light/dark cycle, at a controlled room temperature of $22^{\circ} \mathrm{C}$, with food (Puro Trato, RS, Brazil) and water ad libitum. The animals were used according to

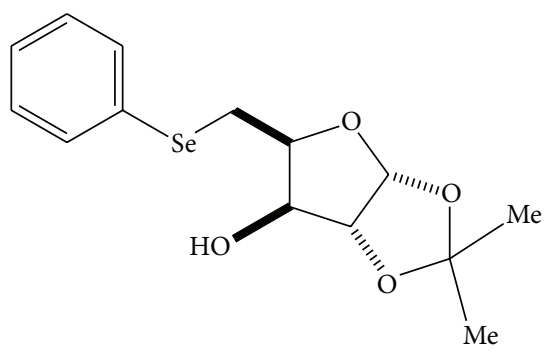

FIGURE 1: Selenofuranoside structure.

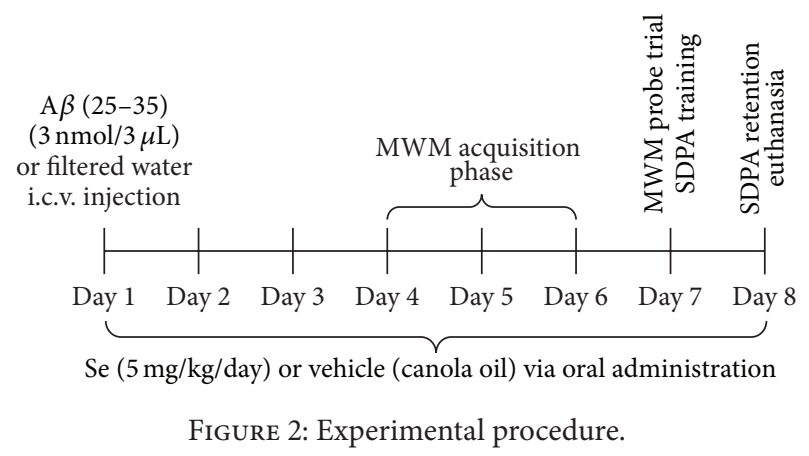

the guidelines of the Committee on Care and Use of Experimental Animal Resources (Federal University of Santa Maria, Santa Maria, Brazil) and all efforts were made to reduce the number of animals being used and their suffering. This study was approved by the Ethics Committee on the Use of Animals of the Federal University of Pampa (Protocol n ${ }^{\circ}$ 012/2013).

Animals were equally separated into four groups $(n=10)$ : control (I); A $\beta$ (II); Se (III); A $\beta+$ Se (IV). Groups III and IV received the Se compound $(5 \mathrm{mg} / \mathrm{kg} /$ day) orally (intragastric gavage) and groups I and II received vehicle (canola oil) every day, until the end of all behavioral tests (Figure 2).

On the first day of treatment, thirty minutes after Se administration, the mice from groups II and IV received a single administration of $\mathrm{A} \beta$ peptide (fragments 25-35) in its aggregated form $(3 \mathrm{nmol} / 3 \mu \mathrm{L}$, i.c.v.). Groups I and III received filtered water $(3 \mu \mathrm{L} /$ per site i.c.v.). The dosage of $\mathrm{A} \beta$ was based on Wang et al. [10]. Intracerebroventricular injection of the $\mathrm{A} \beta$ peptide or vehicle (filtered water) was performed using a stereotaxic (Insight Equipamentos, Brazil) with the bregma fissure as a reference point [11].

Four days after the A $\beta$ peptide (fragments 25-35) injection, the animals have been submitted to behavioral tests. On the eighth day, mice were euthanized and their brains were removed. The whole brains were homogenized in Tris- $\mathrm{HCl}$ (50 mM, pH 7.4) and centrifuged. The supernatant (S1) was used for biochemical analysis.

\subsection{Behavioral Tests}

2.3.1. Morris Water Maze (MWM). Spatial learning and memory were accessed using the MWM task according to Morris [12]. The water maze consisted of a round container $(180 \mathrm{~cm} \times 40 \mathrm{~cm})$ made of black plastic and filled with water 
$\left(22 \pm 2^{\circ} \mathrm{C}\right)$ at a height of $30 \mathrm{~cm}$. The pool was placed in a room with several visual cues for orientation in the maze. The escape platform was made of the same material and color as the pool and it was placed in the middle of the northwest quadrant, $1 \mathrm{~cm}$ below water level. For the acquisition phase, mice were placed next to the wall, facing successively the north, south, east, and west positions. The latency to reach the platform was measured in four trial sessions during 3 consecutive days (corresponding to days 5-7 of treatment) and the animals were allowed to stay in the platform for at least 40 seconds after each trial. Whenever the mice failed to reach the escape platform within 1 min cutoff time, they were retrieved from the pool and placed on it for 40 seconds. Twenty-four hours after the acquisition phase (8th day of treatment), a probe trial was conducted by removing the platform and placing the mice on the north quadrant. The latency as well as the number of crossings over the former platform and the time spent in each quadrant was measured in a single 1-minute trial. The behaviors were videotaped and the experimenter was kept hidden from the animal's sight, but he was able to follow their swimming trajectories.

\subsubsection{Step-Down Passive-Avoidance Test (SDPA). Nonspatial} memory was measured using the SDPA task according to Sakaguchi et al. [13] with modifications in the electric shock and exposure time. During the training session (7th day of treatment), each animal was placed on the platform. When it stepped down and placed its four paws on the grid floor, an electric shock $(0.5 \mathrm{~mA})$ was delivered for 2 seconds. This procedure was repeated until the animal remained 1 min on the platform. The retention test was performed $24 \mathrm{~h}$ after the training. Each animal was placed again on the platform and the step-down latency was measured, considering a cutoff time of $5 \mathrm{~min}$.

2.3.3. Open-Field Test (OPT). Spontaneous locomotor activity was measured in an open-field test [14] performed on the 8 th day of treatment. The floor of the open-field was divided into 9 equal squares. Each animal was placed individually in the center of the arena and the number of segments crossed (4 paws criterion) and rearing was counted in a 4 min session.

\subsection{Biochemical Analysis}

2.4.1. Superoxide Dismutase (SOD) Activity. The activity of SOD was determined as described by Misra and Fridovich [15]. This method is based on the ability of SOD to inhibit the autooxidation of adrenaline to adrenochrome. The color reaction is measured at $480 \mathrm{~nm}$. One unit of enzyme (1IU) is defined as the amount of enzyme required to inhibit the rate of autooxidation of adrenaline to $50 \%$ at $26^{\circ} \mathrm{C}$.

2.4.2. Catalase (CAT) Activity. The CAT activity was determined spectrophotometrically according to the method of Aebi [16], which involves monitoring the consumption of $\mathrm{H}_{2} \mathrm{O}_{2}$ in the presence of the sample (S1) $(20 \mu \mathrm{L})$ at $240 \mathrm{~nm}$. Enzyme activity is expressed in units ( $1 \mathrm{U}$ decomposes $1 \mu \mathrm{mol}$ $\mathrm{H}_{2} \mathrm{O}_{2} /$ min at $\mathrm{pH} 7$ and $25^{\circ} \mathrm{C}$ ).
2.4.3. Glutathione Peroxidase (GPx) Activity. GPx activity was analyzed spectrophotometrically by the method of Paglia and Valentine [17]. GPx analysis was made by adding GSH, $\mathrm{GR}, \mathrm{NADPH}$, and a peroxide to start the reaction, monitored at $340 \mathrm{~nm}$ as NADPH is converted to $\mathrm{NADP}^{+}$.

2.4.4. Glutathione S-Transferase (GST) Activity. GST activity was analyzed spectrophotometrically at $340 \mathrm{~nm}$, as described by Habig et al. [18]. The reaction mixture contained an aliquot of the homogenized tissue ( $\mathrm{S} 1$ ), buffer sodium phosphate $0.1 \mathrm{M} \mathrm{pH} 7$, GSH (100 mM), and 1-chloro-2,4-dinitrobenzene (CDNB) (100 mM), which was used as a substrate. Enzyme activity is expressed as nmol of CDNB conjugated $/ \mathrm{min} / \mathrm{mg}$ protein (30).

2.4.5. Glutathione Reductase (GR). GR activity in S1 was determined as described by Carlberg and Mannervik [19]. In this assay, GSSG is reduced by GR at the expense of NADPH consumption, which is followed at $340 \mathrm{~nm}$. GR activity is proportional to NADPH decay. The enzymatic activity was expressed as nmol NADPH/min/mg protein.

2.4.6. Glutathione (GSH). Briefly, an aliquot of $\mathrm{S} 1$ was incubated with o-phthalaldehyde (OPT) for $15 \mathrm{~min}$ in room temperature [20]. The reaction product was assessed in $420 \mathrm{~nm}$ (with excitation in $350 \mathrm{~nm}$ ). Values were compared to a GSH calibration curve.

2.4.7. Reactive Species ( $R S$ ). The levels of the reactive species were determined by a spectrofluorimetric method, using $2^{\prime}, 7^{\prime}$-dichlorofluorescein diacetate (DCHF-DA) assay [21]. An aliquot of $\mathrm{S} 1$ was incubated with DCHF-DA (1 mM). The oxidation of DCHF-DA to fluorescent dichlorofluorescein was measured for the detection of intracellular RS. The DCF fluorescence intensity emission was recorded at $520 \mathrm{~nm}$ (with $480 \mathrm{~nm}$ excitation) $30 \mathrm{~min}$ after the addition of DCHF-DA to the medium.

2.4.8. Acetylcholinesterase. For the assessment of AChE activity, samples of the whole brain were homogenized in $0.25 \mathrm{M}$ sucrose buffer $(1 / 10, \mathrm{w} / \mathrm{v})$ and centrifuged at $2400 \mathrm{~g}$ at $4^{\circ} \mathrm{C}$ for $15 \mathrm{~min}$. The activity of AChE was carried out according to the method of Ellman et al. [22], using acetylthiocholine as substrate. The activity of AChE was spectrophotometrically measured at $412 \mathrm{~nm}$. The activity of AChE was expressed as nmol AcSCh/hour/mg protein.

2.4.9. Inflammatory Cytokines. Interleukin-1 $\beta$ (IL- $1 \beta$ ), interleukin-6 (IL-6), and tumor necrosis factor alpha (TNF$\alpha$ ) were quantified using ELISA mouse kits for serum and plasma (Sigma-Aldrich, USA).

2.4.10. Protein Determination. Protein concentration was measured by the method of Bradford [23], using bovine serum albumin as a standard. 
TABLE 1: Effect of selenofuranoside on antioxidant enzymes glutathione peroxidase, glutathione reductase, glutathione S-transferase, catalase, and superoxide dismutase in mice exposed to $\mathrm{A} \beta(25-35)$ peptide.

\begin{tabular}{lccccc}
\hline $\begin{array}{l}\text { Groups } \\
(n=10)\end{array}$ & $\begin{array}{c}\text { GPx }(\mathrm{nmol} \\
\text { NADH/min/mg } \\
\text { protein) }\end{array}$ & $\begin{array}{c}\text { GR (nmol conjugated } \\
\text { CDNB/min/mg protein) }\end{array}$ & $\begin{array}{c}\text { GST (nmol conjugated } \\
\text { CDNB/min/mg protein) }\end{array}$ & CAT (U/mg protein) & SOD (U/mg protein) \\
\hline Control & $21.38 \pm 1.10$ & $24.90 \pm 2.15$ & $566.6 \pm 26.1$ & $0.628 \pm 0.038$ & $51.86 \pm 2.10$ \\
Se & $18.78 \pm 1.19$ & $21.96 \pm 1.24$ & $707.4 \pm 64.8$ & $0.548 \pm 0.102$ & $56.36 \pm 2.71$ \\
$\mathrm{~A} \beta$ & $22.29 \pm 1.45$ & $26.93 \pm 1.66$ & $653.1 \pm 34.6$ & $0.676 \pm 0.063$ & $33.85 \pm 4.31^{*}$ \\
$\mathrm{Se}+\mathrm{A} \beta$ & $19.26 \pm 1.26$ & $25.56 \pm 2.75$ & $699.7 \pm 47.1$ & $0.721 \pm 0.083$ & $49.11 \pm 1.88$ \\
\hline
\end{tabular}

Data are reported as mean \pm S.E.M.

${ }^{*} p<0.05$ as compared to the control group.

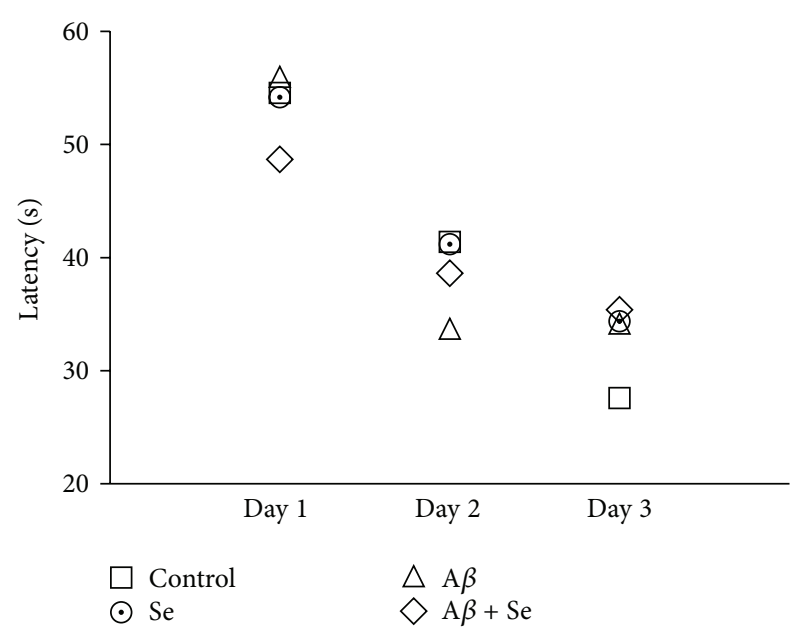

FIGURE 3: Effect of selenofuranoside on the latency (s) to reach the platform in the acquisition phase in mice with amyloid- $\beta$ induced memory deficit in Morris water maze test $(n=10)$. Data are reported as means.

2.5. Statistical Analysis. Data are expressed as mean \pm S.E.M. A statistical analysis was performed using a two-way ANOVA followed by the Tukey's test. The main effects are presented only when the interaction effect was nonsignificant. Values of $p<0.05$ were considered statistically significant.

\section{Results}

\subsection{Behavioral Tests}

3.1.1. Water Maze Test. In the acquisition phase of the WMT, no difference was observed between groups regarding the latency to reach the platform. There was not any type of interaction among treatments or any kind of main effect. However, it is possible to see a significant difference between the days in the acquisition phase in all groups $\left(F_{1,36}=19.40\right.$, $p<0.001)$, demonstrating the main effect of time in learning ability (Figure 3).

In the probe test, a significant increase in latency to reach the former platform for the $\mathrm{A} \beta$ group compared to the control group was observed (Figure 4(a); $F_{1,36}=4.64$, $p<0.05)$. Also, it is possible to identify a difference in the total time spent on the quadrant where the platform was located (Figure $4(\mathrm{~b})$ ). The $\mathrm{A} \beta$ group presented a significant decrease in this parameter compared to the control group, as well as the Se group. Nevertheless, the $\mathrm{Se}+\mathrm{A} \beta$ group showed no difference compared to the control group, demonstrating a possible interaction between $\mathrm{Se}$ and $\mathrm{A} \beta\left(F_{1,36}=18.64\right.$, $p<0.001)$.

Two-way ANOVA revealed a significant $\mathrm{A} \beta \times$ Se interaction $\left(F_{1,36}=5.113, p<0.05\right)$ in the number of crossings over the former platform location (Figure 4(c)). Post hoc comparisons showed that the group that received $\mathrm{A} \beta$ via i.c.v. presented a significant decrease in the number of crossings compared to the control group, while $\mathrm{Se}$ and $\mathrm{Se}+\mathrm{A} \beta$ groups showed no difference.

3.1.2. Step-Down Passive-Avoidance Test. During the acquisition phase in the passive avoidance, there was no difference in the step-down latency time among groups $\left(F_{1,36}=0.721 ; p<\right.$ 0.05 ) (Figure 2). Two-way ANOVA of the step-down latency time in retention trial did not show $\mathrm{A} \beta \times$ Se interaction $\left(F_{1,36}=2.185 ; p<0.05\right)$, demonstrating a main effect of $\mathrm{A} \beta$ $\left(F_{1,36}=12.420 ; p<0.01\right)$.

Post hoc comparisons showed that the $\mathrm{A} \beta$ peptide significantly decreased the step-down latency time in retention trial (Figure 5), while Se partially prevented the alteration caused by $\mathrm{A} \beta$.

3.1.3. Open-Field Test. The spontaneous locomotor activity measured in the open-field test did not differ significantly between the groups. Two-way ANOVA for the number of crossings $\left(F_{1,36}=1.084 ; p<0.05\right)$ and rearings $\left(F_{1,36}=0.071 ; p<0.05\right)$ revealed no significant differences (Figure 6).

\subsection{Biochemical Analyses}

3.2.1. Oxidative Stress Parameters. Regarding the antioxidant enzymes, an alteration only in superoxide dismutase was observed. Mice that received the $\mathrm{A} \beta$ fragment $25-35$ via i.c.v. presented a decrease in SOD activity (65\%) in brain samples, which was significantly different from the control group $\left(F_{1,36}=19,72, p<0.001\right)$. Selenofuranoside therapy was effective to restore enzyme activity at control levels. All the other antioxidant enzymes assessed in this experiment showed no significant alteration (Table 1).

A main effect of $\mathrm{A} \beta$ on GSH levels $\left(F_{1,36}=30.93 ; p<\right.$ 0.001 ) was observed in the $A \beta$ group. Increased GSH levels 


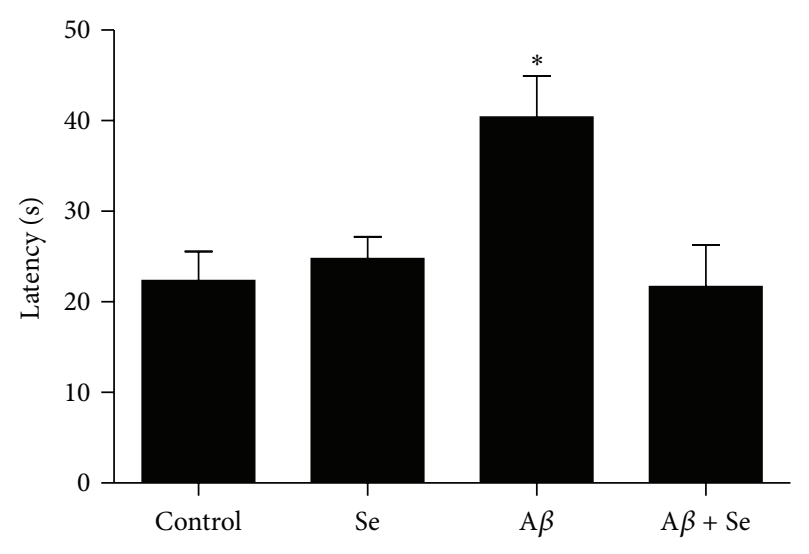

(a)

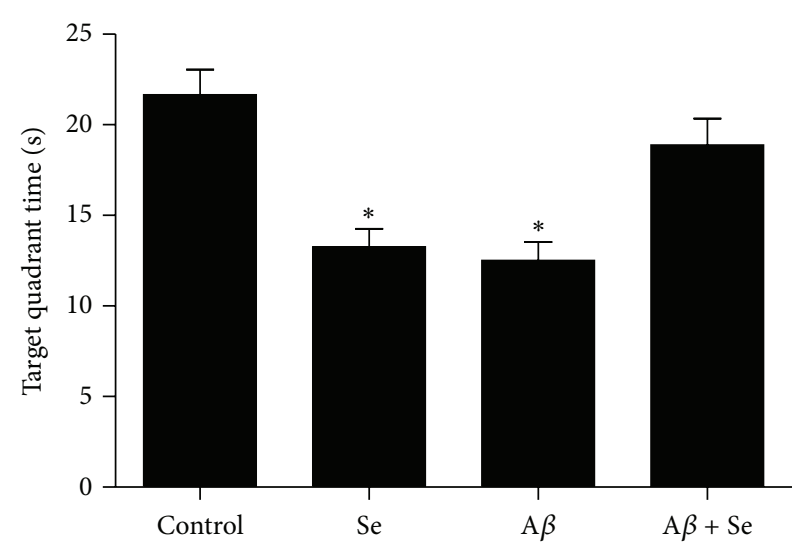

(b)

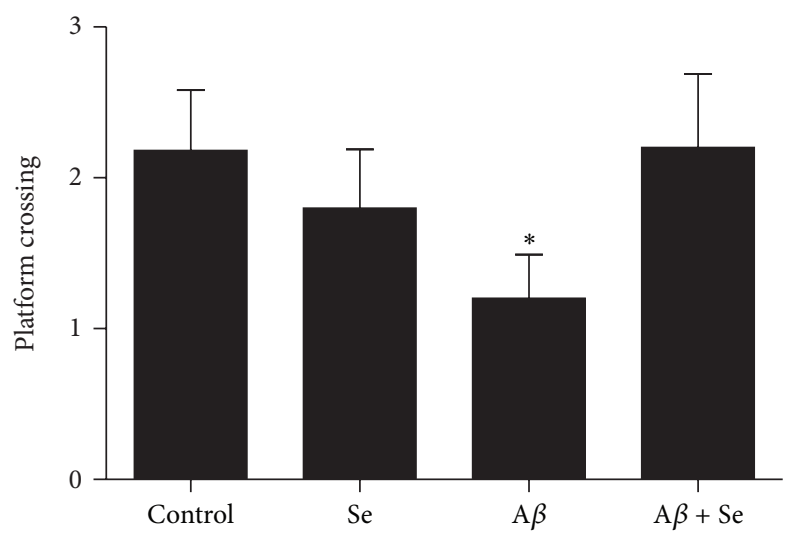

(c)

Figure 4: Effect of selenofuranoside on amyloid- $\beta$ induced memory deficit in Morris water maze test $(n=10)$. (a) Latency (s) to reach the platform in the probe test (retention phase). (b) Time (s) spent in the former platform quadrant in the probe test. (c) Number of crossings over the former platform position, in the probe test. Data are reported as means \pm S.E.M. ${ }^{*} p<0.05$ as compared to the control group.

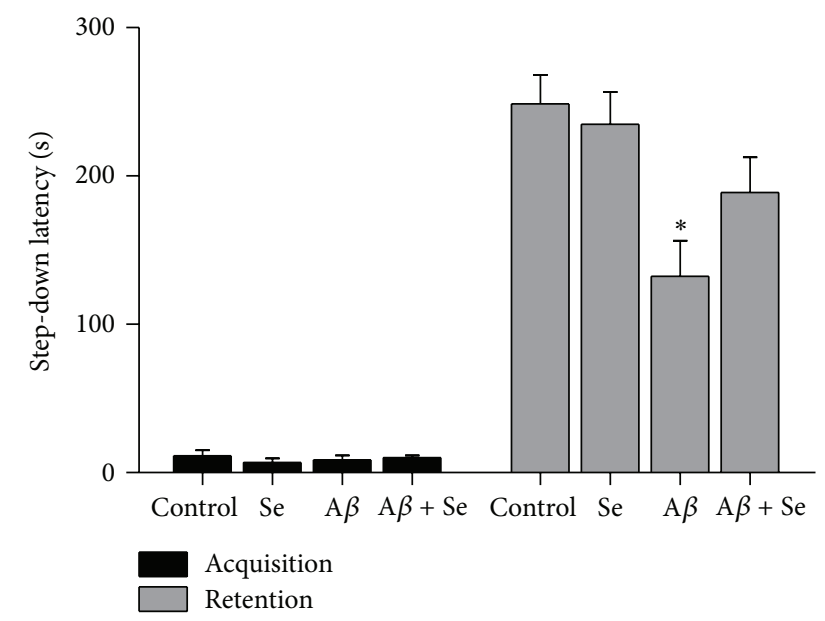

FIGURE 5: Effect of selenofuranoside on the step-down latency (s) in mice with amyloid- $\beta$ induced memory deficit on the passiveavoidance test $(n=10)$. Data are reported as means \pm S.E.M. ${ }^{*} p<0.05$ as compared to the control group.

were detected in the $\mathrm{A} \beta$ group (40\%) as well as in the $\mathrm{Se}+$ $\mathrm{A} \beta$ group (52\%) (Figure 7).
Two-way ANOVA demonstrated a significant $\mathrm{A} \beta \times \mathrm{Se}$ interaction $(F=20.92 ; p<0.001)$ in RS levels $(55 \%)$. An increase in this parameter was found in the $\mathrm{A} \beta$ group, compared to the control group (Figure 8). Selenofuranoside was able to reduce RS to the control levels, thus demonstrating a possible protective effect of Se.

3.2.2. AChE Activity. The $\mathrm{A} \beta$ fragment significantly $\left(F_{1,36}=\right.$ $11.30, p<0.01)$ increased AChE activity $(21 \%)$ in the whole mice brain compared to the control group. Selenofuranoside therapy was able to prevent this increase (Figure 9).

3.2.3. Cytokines. There was a significant $\mathrm{A} \beta \times$ Se interaction $\left(F_{1,9}=69.65, p<0.001\right)$ in IL-6 cytokine (Figure 10). Post hoc tests showed a significant increase in the Se and $A \beta$ groups compared to control. In the $\mathrm{Se}+\mathrm{A} \beta$ group, IL- 6 levels returned to control levels.

IL-1 $\beta$ and TNF- $\alpha$ showed no significant difference.

\section{Discussion}

In the present study, we evaluated the effect of an organoselenium compound, selenofuranoside, in a model of Alzheimerlike sporadic dementia induced by intracerebroventricular 


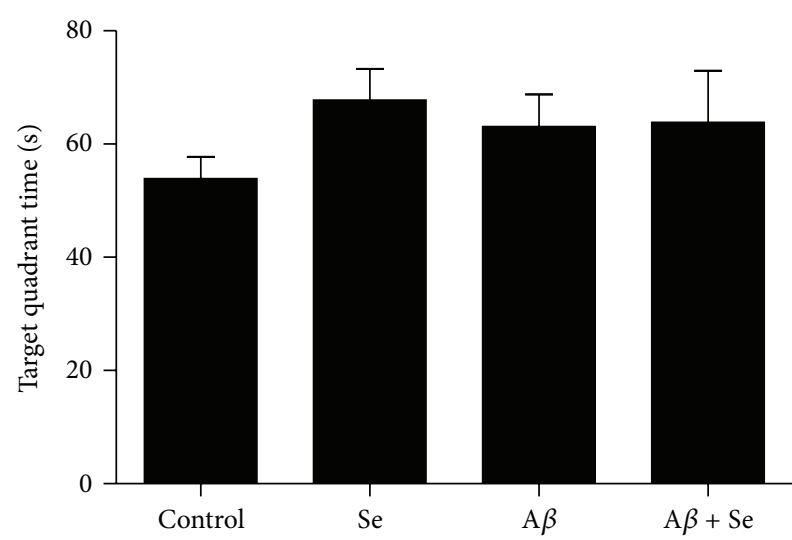

(a)

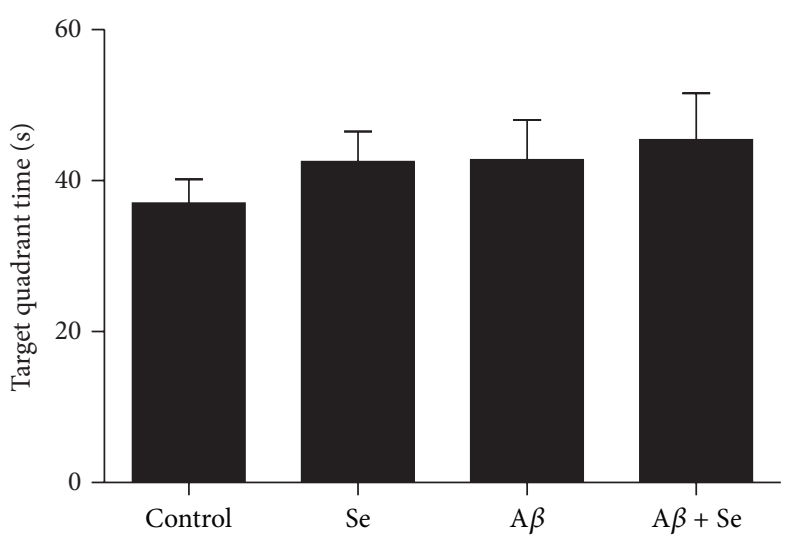

(b)

Figure 6: Effect of selenofuranoside in mice with memory deficit induced by amyloid- $\beta$ on the open-field test $(n=10)$. (a) Number of crossings and (b) number of rearings. Data are reported as means \pm S.E.M.

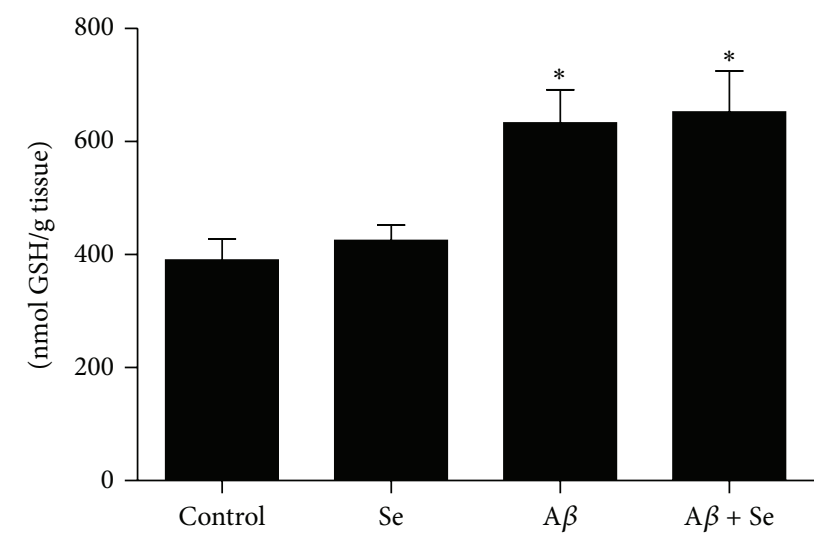

Figure 7: Effect of selenofuranoside on glutathione levels in mice brain after amyloid- $\beta$ treatment $(n=10)$. Data are reported as mean \pm S.E.M. and expressed as nmol of GSH per gram of tissue. ${ }^{*} p<$ 0.05 as compared to the control group.

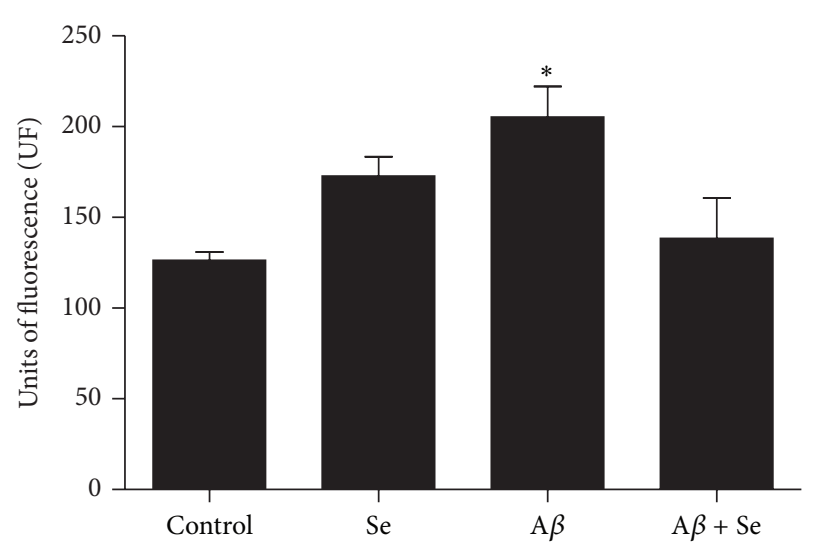

FIGURE 8: Effect of selenofuranoside on reactive species levels in mice brain after amyloid- $\beta$ treatment $(n=10)$. Data are reported as mean \pm S.E.M. and expressed as UF. ${ }^{*} p<0.05$ as compared to the control group.

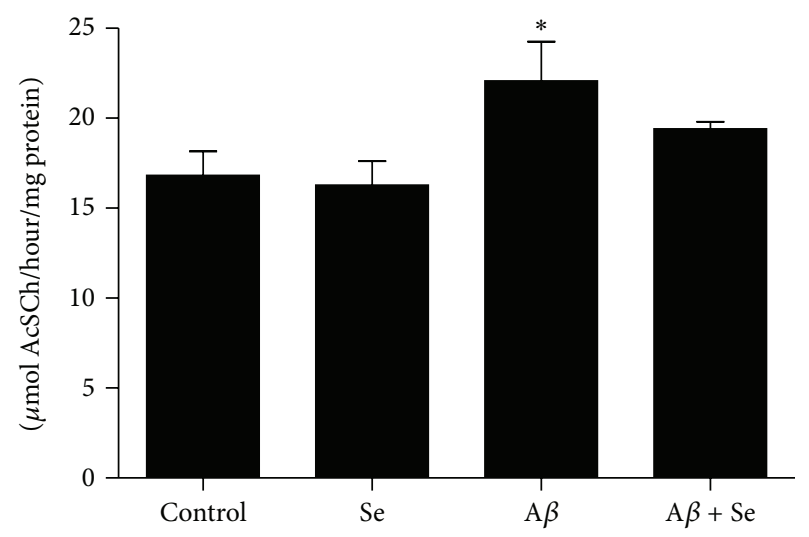

FIGURE 9: Effect of selenofuranoside on acetylcholinesterase activity in mice brain after amyloid- $\beta$ treatment $(n=10)$. Data are reported as mean \pm S.E.M. and expressed as $\mu \mathrm{mol} \mathrm{AcSCh} /$ hour $/ \mathrm{mg}$ protein. ${ }^{*} p<0.05$ as compared to the control group.

administration of amyloid-beta peptide fragment (25-35). In order to assign new therapeutic approaches, the synthetic antioxidant compounds, such as organoselenium compounds, have been given more attention due to the fact that these compounds present important biological activities.

According to the results, the $\mathrm{A} \beta_{25-35}$ i.c.v. injection caused mild memory impairment as described in other papers [7, 24]. This can be concluded by the increased step-down latency in SDPA test and also by the increased latency to reach the former platform location in the MWM test. The $\mathrm{A} \beta_{25-35}$ group also showed a reduction in the number of crossings in the former platform location and also in the time spent in the target quadrant during the MWM test. Selenofuranoside was effective to ameliorate most of these evaluated parameters.

Aiming to provide more information related to cognitive impairment and Se intervention, oxidative stress, inflammatory cytokines, and AChE activity were assessed.

Although the role of oxidative stress and reactive species in $\mathrm{AD}$ is not clear, many papers have shown that lipid 


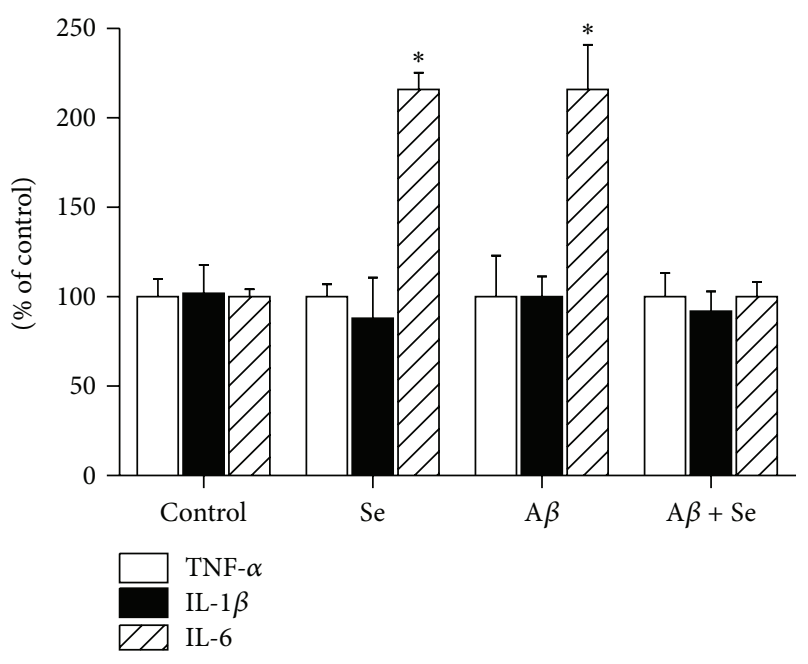

FIGURE 10: Effect of selenofuranoside on cytokines levels in mice brain after amyloid- $\beta$ treatment $(n=3)$. Data are reported as mean \pm S.E.M. and expressed as relative percentage of control. ${ }^{*} p<0.05$ as compared to the control group.

peroxidation and reactive species are increased in an $\mathrm{AD}$ brain compared to brains of healthy persons in the same age range, indicating that these increased factors are not merely a consequence of aging [25]. One theory is that methionine35 of $\mathrm{A} \beta_{(1-42)}$ is essential for oxidative stress in vivo in $\mathrm{AD}$ models and presumably in AD brains as well [26]. Even though the $\alpha$-helix structure of $\mathrm{A} \beta_{(1-42)}$ is crucial for the production of oxidative stress [27], apparently the C-terminal Met-35 of $\mathrm{A} \beta_{(25-35)}$ fragment also have a strong power to cause mitochondrial dysfunction [28].

The involvement of oxidative stress in memory loss can be seen in our results, since it was possible to see a decrease in SOD activity, one of the most important antioxidant enzymes in most living organisms. This enzyme catalyzes the dismutation of superoxide radical, which is produced as a deleterious byproduct in mitochondrial respiration due to electron leakage. Since mitochondrial dysfunction is regarded as a major causative factor in many neurodegenerative diseases [29], superoxide anion may have accumulated due to the reduction in enzyme activity in the $\mathrm{A} \beta$ group. This may be reflected as an increase in reactive species, also seen in the $\mathrm{A} \beta$ group. It is likely that a reduction in SOD activity is a primordial event in this process that culminates on reactive species accumulation. These, consecutively, could be responsible for the deleterious effects in the brain.

Selenofuranoside may form selenolate radical $\left(\mathrm{RSe}^{-1}\right)$ in a thiol-rich environment, similarly as diphenyl diselenide and ebselen [30]. Selenolate radical can react with $\mathrm{H}_{2} \mathrm{O}_{2}$ and form selenic acid, which then reacts with thiol group ( $\mathrm{RSH}$ ) to form selenyl sulfide and it can be regenerated back to selenide. This could to some extent explain the reduction in RS levels. However, the most important finding concerning oxidative stress was the ability to restore SOD activity, which probably has most effect on RS levels. Another organoselenium compound, as $p, p^{\prime}$-methoxyl-diphenyl diselenide, has shown similar effects on SOD activity in different Alzheimer models [31].

Apart from SOD, we did not find significant alterations in other antioxidant enzymes activities, such as GPx, GR, and CAT, nor in xenobiotic detoxification enzyme GST. However, we detected an increase in GSH levels in the $\mathrm{A} \beta$ group that was not improved by the selenofuranoside treatment. Since not only GSH is responsible for nonenzymatic oxidative stress balance but it is also used for conjugation reactions to eliminate xenobiotics, the increase seen in the $\mathrm{A} \beta$ group may be caused by a response to higher levels of RS or a foreign substance.

Beyond oxidative stress, many studies also indicate an association between inflammation and $\mathrm{AD}$. In vitro studies show increased inflammatory cytokines in brain cell cultures submitted to $\mathrm{A} \beta$ and the role of microglial activation in $\operatorname{AD}[32,33]$. Our results showed a significant difference in IL- 6 in the $\mathrm{A} \beta$ and Se groups compared to control. However, no significant differences were detected in other cytokines evaluated, probably due to different animal model used and/or amyloid-beta fragment. Most in vivo studies that show the relationship between inflammatory markers and Alzheimer's disease are conducted on rats or transgenic mice.

A possible involvement of IL-6 on memory processes was observed after knockout mice for this particular cytokine exhibit faster learning skills in the radial maze test through 30 days [34], meaning that this cytokine may be somehow involved in spatial memory. Thus, we verified that animals that received amyloid- $\beta$ presented an increase on IL- 6 levels and Se therapy protected this parameter. However, Se itself caused an increase on this parameter. We cannot explain the exact reason for this, and other studies need to be carried out for better understanding of this effect. On the other hand, we believe that the main result in this parameter is related to the combination of amyloid- $\beta$ and Se, in which we verified IL-6 levels similar to the control group.

In addition, many researchers are trying to develop new therapies to treat AD. Acetylcholinesterase inhibitors are still largely used, since it has been hypothesized that cognition impairment may be related to a decrease in acetylcholine levels or an increase in AChE activity [35]. We observed an increase in $\mathrm{AChE}$ activity after the $\mathrm{A} \beta$ i.c.v. injection, which may explain the results seen in the memory tests employed. Selenofuranoside was able to restore AChE activity as well as memory impairment observed in the $\mathrm{A} \beta$ group.

In conclusion, selenofuranoside could be helpful as a new therapeutic research to manage memory loss and impaired cognition since it can modulate AChE activity and protect against reduced SOD activity and increased RS levels after $\mathrm{A} \beta_{25-35}$ i.c.v. administration. Also, when administered along with $\mathrm{A} \beta$, selenofuranoside was able to reduce IL- 6 concentration to control levels. These effects may be related to the protection against memory loss and cognition impairment presented in behavioral tests. Further studies have to be conducted to evaluate selenofuranoside biological activity as well as its toxicity in order to consider this compound as an alternative therapy for the Alzheimer's disease. 


\section{Conflict of Interests}

The authors declare that they have no conflict of interests.

\section{Acknowledgments}

The financial support by CNPq and FAPERGS is gratefully acknowledged. Francielli Weber Santos is the recipient of $\mathrm{CNPq}$ fellowship. CAPES is acknowledged for financial support for Doctoral Student fellowship to Aryele Pinto Izaguirry and FAPERGS for MSc fellowship to Natasha Frasson Pavin.

\section{References}

[1] K. Blennow, M. J. de Leon, and H. Zetterberg, "Alzheimer's disease," The Lancet, vol. 368, no. 9533, pp. 387-403, 2006.

[2] D. J. Selkoe, "Amyloid beta-protein and the genetics of Alzheimer's disease," The Journal of Biological Chemistry, vol. 271, no. 31, pp. 18295-18298, 1996.

[3] M. E. Clementi, S. Marini, M. Coletta, F. Orsini, B. Giardina, and F. Misiti, "Abeta(31-35) and Abeta(25-35) fragments of amyloid beta-protein induce cellular death through apoptotic signals: role of the redox state of methionine-35," FEBS Letters, vol. 579, no. 13, pp. 2913-2918, 2005.

[4] S. T. Ferreira, J. R. Clarke, T. R. Bomfim, and F. G. de Felice, "Inflammation, defective insulin signaling, and neuronal dysfunction in Alzheimer's disease," Alzheimer's \& Dementia, vol. 10, no. 1, pp. S76-S83, 2014.

[5] L. M. Vargas, M. B. Soares, A. P. Izaguirry et al., "Cadmium inhibits the ovary $\delta$-aminolevulinate dehydratase activity in vitro and ex vivo: protective role of seleno-furanoside," Journal of Applied Toxicology, vol. 33, no. 7, pp. 679-684, 2013.

[6] S. G. N. Wollenhaupt, A. T. Soares, W. G. Salgueiro et al., "Seleno- and telluro-xylofuranosides attenuate Mn-induced toxicity in C. elegans via the DAF-16/FOXO pathway," Food and Chemical Toxicology, vol. 64, pp. 192-199, 2014.

[7] S. Pinton, A. C. Souza, M. H. M. Sari, R. M. Ramalho, C. M. P. Rodriguesb, and C. W. Nogueiraa, "P,p'-Methoxyl-diphenyl diselenide protects against amyloid- $\beta$ induced cytotoxicity in vitro and improves memory deficits in vivo," Behavioural Brain Research, vol. 247, pp. 241-247, 2013.

[8] S. Pinton, T. B. Sampaio, R. M. Ramalho, C. M. P. Rodrigues, and C. W. Nogueira, "p,p'-Methoxyl-diphenyl diselenide prevents neurodegeneration and glial cell activation induced by streptozotocin in rats," Journal of Alzheimer's Disease, vol. 33, no. 1, pp. 133-144, 2013.

[9] H. C. Braga, H. A. Stefani, M. W. Paixão, F. W. Santos, and D. S. Lüdtke, "Synthesis of $5^{\prime}$-seleno-xylofuranosides," Tetrahedron, vol. 66, no. 19, pp. 3441-3446, 2010.

[10] H. H. Wang, C. J. Chou, J. F. Liao, and C. F. Chen, "Dehydroevodiamine attenuates $\beta$-amyloid peptide-induced amnesia in mice," European Journal of Pharmacology, vol. 413, no. 2-3, pp. 221-225, 2001.

[11] T. J. Haley and W. G. McCormick, "Pharmacological effects produced by intracerebral injection of drugs in the conscious mouse," British Journal of Pharmacology and Chemoterapy, vol. 12, no. 1, pp. 12-15, 1957.

[12] R. Morris, "Developments of a water-maze procedure for studying spatial-learning in the rat," Journal of Neuroscience Methods, vol. 11, no. 1, pp. 47-60, 1984.
[13] M. Sakaguchi, M. Koseki, M. Wakamatsu, and E. Matsumura, "Effects of systemic administration of beta-casomorphin-5 on learning and memory in mice," European Journal of Pharmacology, vol. 530, no. 1-2, pp. 81-87, 2006.

[14] R. N. Walsh and R. A. Cummins, "The open-field test: a critical review," Psychological Bulletin, vol. 83, no. 3, pp. 482-504, 1976.

[15] H. P. Misra and I. Fridovich, "The role of superoxide anion in the autoxidation of epinephrine and a simple assay for superoxide dismutase," The Journal of Biological Chemistry, vol. 247, no. 10, pp. 3170-3175, 1972.

[16] H. Aebi, "Catalase in vitro," Methods in Enzymology, vol. 105, pp. 121-126, 1984.

[17] D. E. Paglia and W. N. Valentine, "Studies on the quantitative and qualitative characterization of erythrocyte glutathione peroxidase," The Journal of Laboratory and Clinical Medicine, vol. 70, no. 1, pp. 158-169, 1967.

[18] W. H. Habig, M. J. Pabst, and W. B. Jakoby, "Glutathione $S$ transferases. The first enzymatic step in mercapturic acid formation," Journal of Biological Chemistry, vol. 249, no. 22, pp. 7130-7139, 1974.

[19] I. Carlberg and B. Mannervik, "Glutathione reductase," Methods in Enzymology, vol. 113, pp. 484-490, 1985.

[20] P. J. Hissin and R. Hilf, "A fluorometric method for determination of oxidized and reduced glutathione in tissues," Analytical Biochemistry, vol. 74, no. 1, pp. 214-226, 1976.

[21] Q. Chen, E. J. Vazquez, S. Moghaddas, C. L. Hoppel, and E. J. Lesnefsky, "Production of reactive oxygen species by mitochondria-central role of complex III," The Journal of Biological Chemistry, vol. 278, no. 38, pp. 36027-36031, 2003.

[22] G. L. Ellman, K. D. Courtney, V. Andres Jr., and R. M. Featherstone, "A new and rapid colorimetric determination of acetylcholinesterase activity," Biochemical Pharmacology, vol. 7, no. 2, pp. 88-90, 1961.

[23] M. M. Bradford, "A rapid and sensitive method for the quantitation of microgram quantities of protein utilizing the principle of protein dye binding," Analytical Biochemistry, vol. 72, no. 1-2, pp. 248-254, 1976.

[24] A. Díaz, K. Rojas, B. Espinosa et al., "Aminoguanidine treatment ameliorates inflammatory responses and memory impairment induced by amyloid-beta 25-35 injection in rats," Neuropeptides, vol. 48, no. 3, pp. 153-159, 2014.

[25] X. Wang, W. Wang, L. Li, G. Perry, H. G. Lee, and X. Zhu, "Oxidative stress and mitochondrial dysfunction in Alzheimer's disease," Biochimica et Biophysica Acta (BBA)-Molecular Basis of Disease, vol. 1842, no. 8, pp. 1240-1247, 2014.

[26] A. M. Swomley, S. Förster, J. T. Keeney et al., "Abeta, oxidative stress in Alzheimer disease: evidence based on proteomics studies," Biochimica et Biophysica Acta-Molecular Basis of Disease, vol. 1842, no. 8, pp. 1248-1257, 2014.

[27] J. Kanski, M. Aksenova, C. Schöneich, and D. A. Butterfield, "Substitution of isoleucine-31 by helical-breaking proline abolishes oxidative stress and neurotoxic properties of Alzheimer's amyloid $\beta$-peptide," Free Radical Biology and Medicine, vol. 32, no. 11, pp. 1205-1211, 2002.

[28] S. Varadarajan, J. Kanski, M. Aksenova, C. Lauderback, and D. A. Butterfield, "Different mechanisms of oxidative stress and neurotoxicity for Alzheimer's Abeta(1-42) and Abeta(25-35)," Journal of the American Chemical Society, vol. 123, no. 24, pp. 5625-5631, 2001.

[29] M. H. Yana, X. Wang, and X. Zhu, "Mitochondrial defects and oxidative stress in Alzheimer disease and Parkinson disease," Free Radical Biology and Medicine, vol. 62, pp. 90-101, 2013. 
[30] W. Hassan, M. Ibrahim, and J. B. T. Rocha, "Towards the mechanism and comparative effect of diphenyl diselenide, diphenyl ditelluride and ebselen under various pathophysiological conditions in rat's kidney preparation," Chemico-Biological Interactions, vol. 182, no. 1, pp. 52-58, 2009.

[31] S. Pinton, J. T. da Rocha, B. M. Gai, M. Prigol, L. V. da Rosa, and C. W. Nogueira, "Neuroprotector effect of $p, p^{\prime}$ methoxyl-diphenyl diselenide in a model of sporadic dementia of Alzheimer's type in mice: contribution of antioxidant mechanism," Cell Biochemistry and Function, vol. 29, no. 3, pp. 235243, 2011.

[32] H. G. Kim, M. Moon, J. G. Choi et al., "Donepezil inhibits the amyloid-beta oligomer-induced microglial activation in vitro and in vivo," NeuroToxicology, vol. 40, pp. 23-32, 2014.

[33] K. Bhaskar, N. Maphis, G. Xu et al., "Microglial derived tumor necrosis factor- $\alpha$ drives Alzheimer's disease-related neuronal cell cycle events," Neurobiology of Disease, vol. 62, pp. 273-285, 2014.

[34] D. Braida, P. Sacerdote, A. E. Panerai et al., "Cognitive function in young and adult IL (interleukin)-6 deficient mice," Behavioural Brain Research, vol. 153, no. 2, pp. 423-429, 2004.

[35] M. Singh, M. Kaur, H. Kukreja, R. Chugh, O. Silakari, and D. Singh, "Acetylcholinesterase inhibitors as Alzheimer therapy: from nerve toxins to neuroprotection," European Journal of Medicinal Chemistry, vol. 70, pp. 165-188, 2013. 


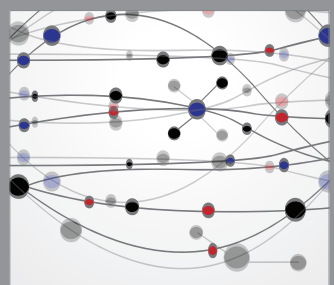

The Scientific World Journal
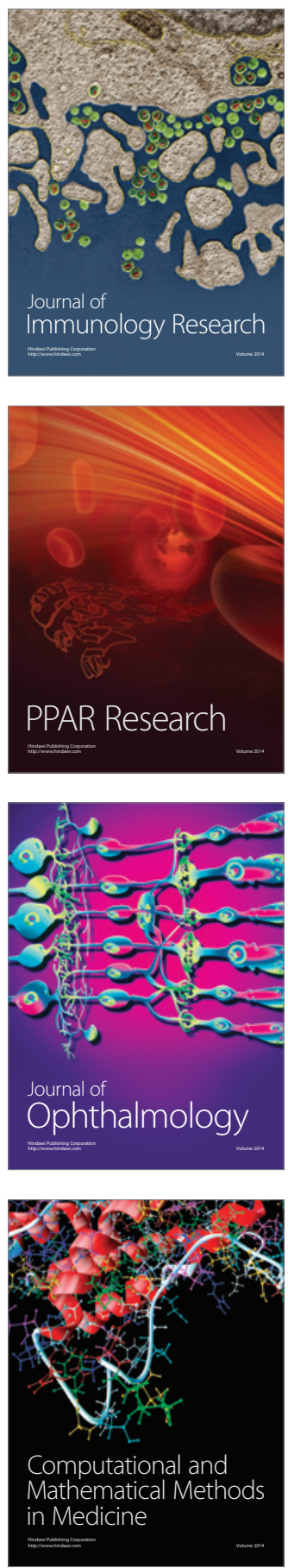

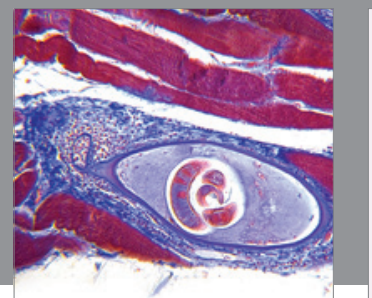

Gastroenterology

Research and Practice
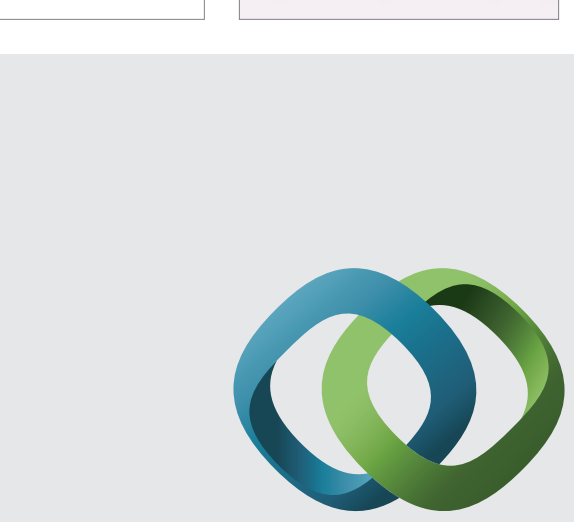

\section{Hindawi}

Submit your manuscripts at

http://www.hindawi.com
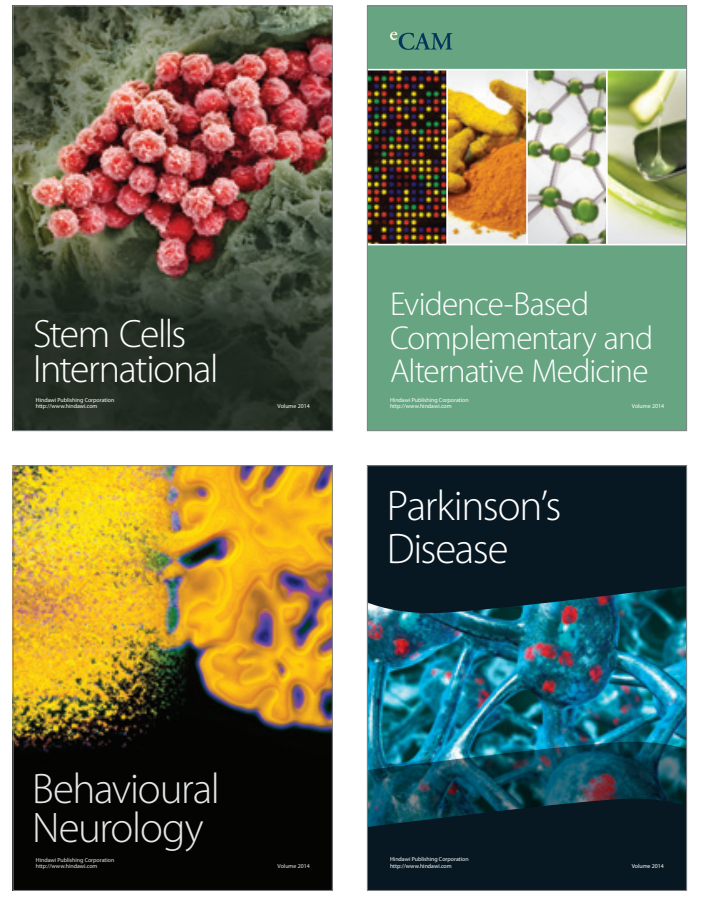
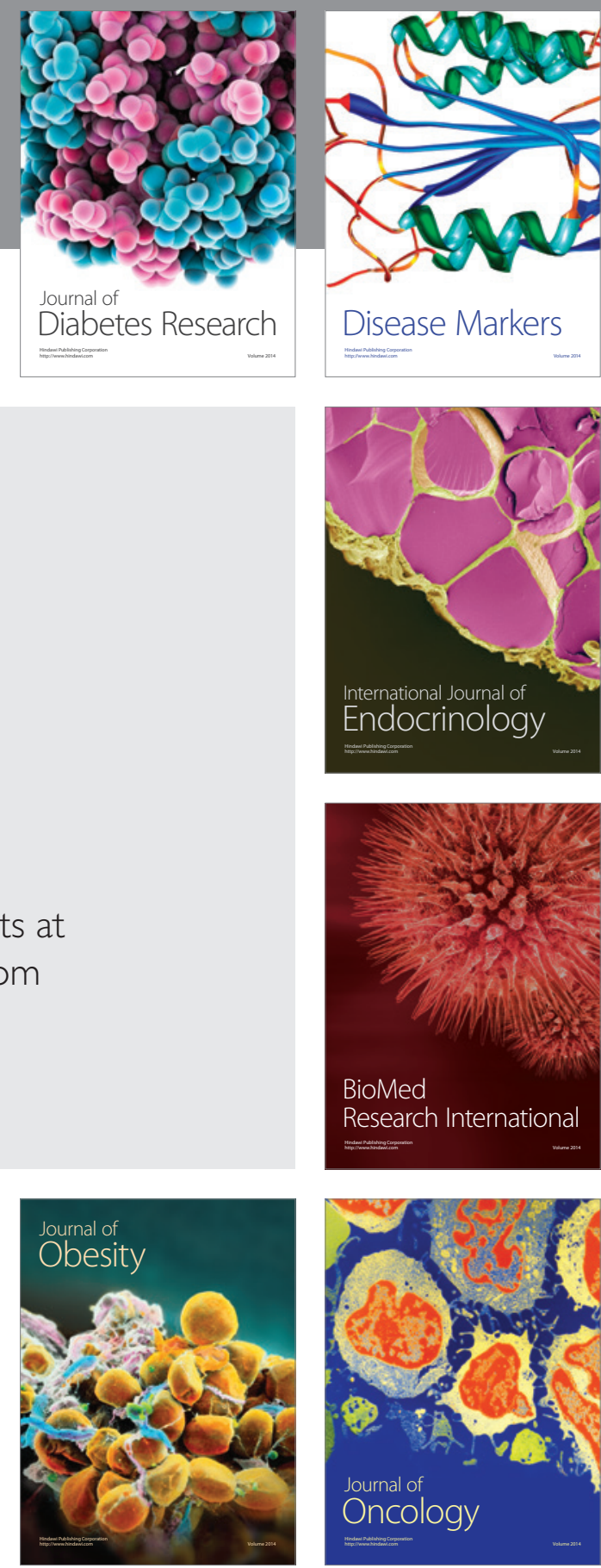

Disease Markers
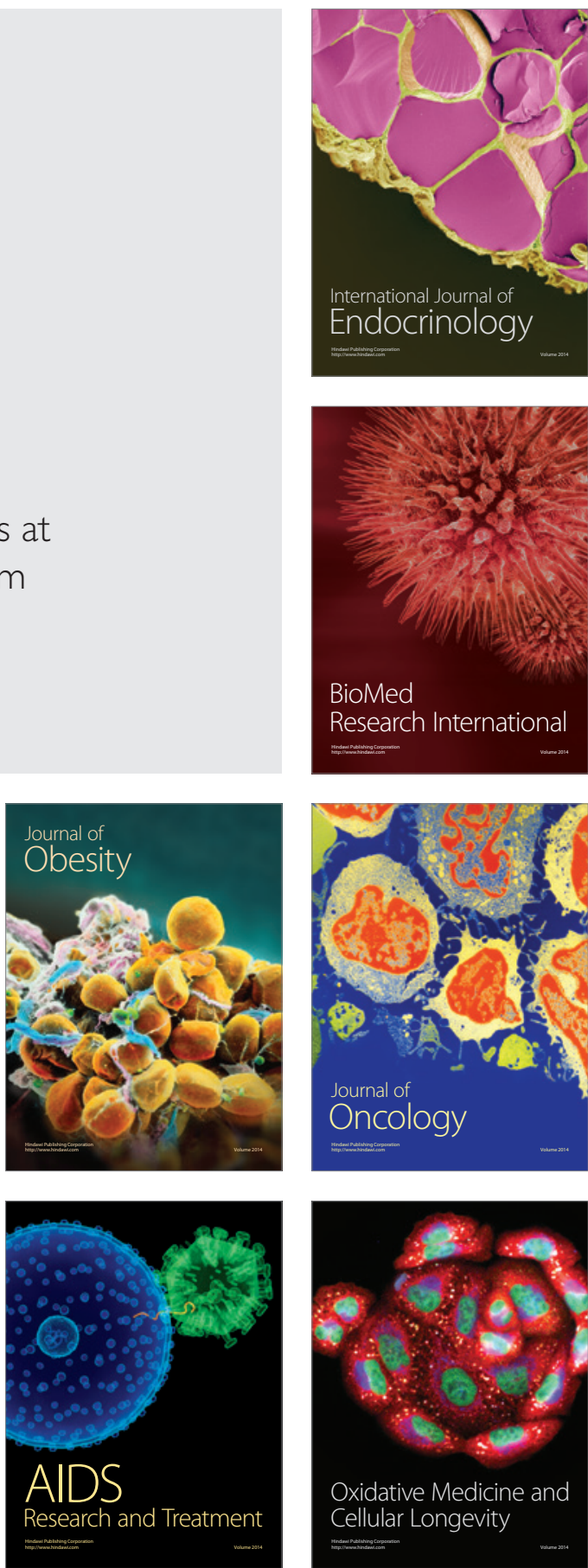